\title{
Clinical implications of decision making in colorectal polypectomy: an international survey of Western endoscopists suggests priorities for change
}

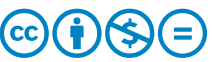

\author{
Authors
}

David J. Tate1,2,5, Lobke Desomer ${ }^{3}$, Steven J. Heitman4, Nauzer Forbes ${ }^{4}$, Nicholas G. Burgess ${ }^{1}$, Halim Awadie ${ }^{8}$, lan M. Gralnek $^{8}$, Jeroen Geldof ${ }^{5}$, Danny De Looze ${ }^{5}$, Douglas Rex ${ }^{6}$, John Anderson ${ }^{7}$, Michael J. Bourke ${ }^{1,2}$ tice against the best available contemporary evidence. effect may be attenuated by variations in polypectomy, with multiple techniques available and a wide range of experience amongst endoscopists. We assessed current prac-

Methods An online survey was distributed to members of the gastroenterological and surgical societies of seven countries during July 2017. Images of colorectal polyps were presented and respondents requested to provide the polypectomy technique they would employ in their daily practice. Responses were compared to the evidence-based techniques in the 2017 ESGE Colorectal Polypectomy Guideline.

Results In total, 707 endoscopists (627 physicians, 71 surgeons, 9 nurse endoscopists, median practice duration 18 years) completed the survey. Of these, $3.1 \%$ selected hot biopsy forceps and $5.2 \%$ hot snare polypectomy (without submucosal lifting) to remove a $3 \mathrm{~mm}$ ascending colon polyp. Only $43.3 \%$ selected cold snare polypectomy (CSP) to remove an $8 \mathrm{~mm}$ ascending colon polyp. Surgical referral was selected by $16.7 \%$ of respondents for a $45 \mathrm{~mm}$ transverse colon polyp without endoscopic evidence of submucosal invasive cancer (SMIC). Endoscopic resection was selected by $12.0 \%$ for an $80 \mathrm{~mm}$ sigmoid polyp with imaging consistent with deep SMIC, and a further $26.4 \%$ selected tertiary endoscopist referral, suggesting they had not appreciated that it was endoscopically unresectable.

Conclusion CSP is underutilized for small polyp resection despite its favorable safety and efficacy. Benign polyps are commonly referred for surgery and overt SMIC is underappreciated using endoscopic imaging. Addressing these issues may reduce diathermy-related adverse events, surgery, and unnecessary colonoscopic procedures for patients and reduce rates of post-colonoscopy colorectal cancer.

\section{Introduction}

Colonoscopy has been shown to prevent colorectal cancer [1] and deaths from colorectal cancer [2]. The key to this effect is the detection and resection of premalignant polyps. Colonos- copy and polypectomy have been shown to be inversely related to post-colonoscopy colorectal cancer (PCCRC) and death from PCCRC [3]. This effect is likely to be smaller than is potentially achievable since polypectomy has been shown to be commonly 


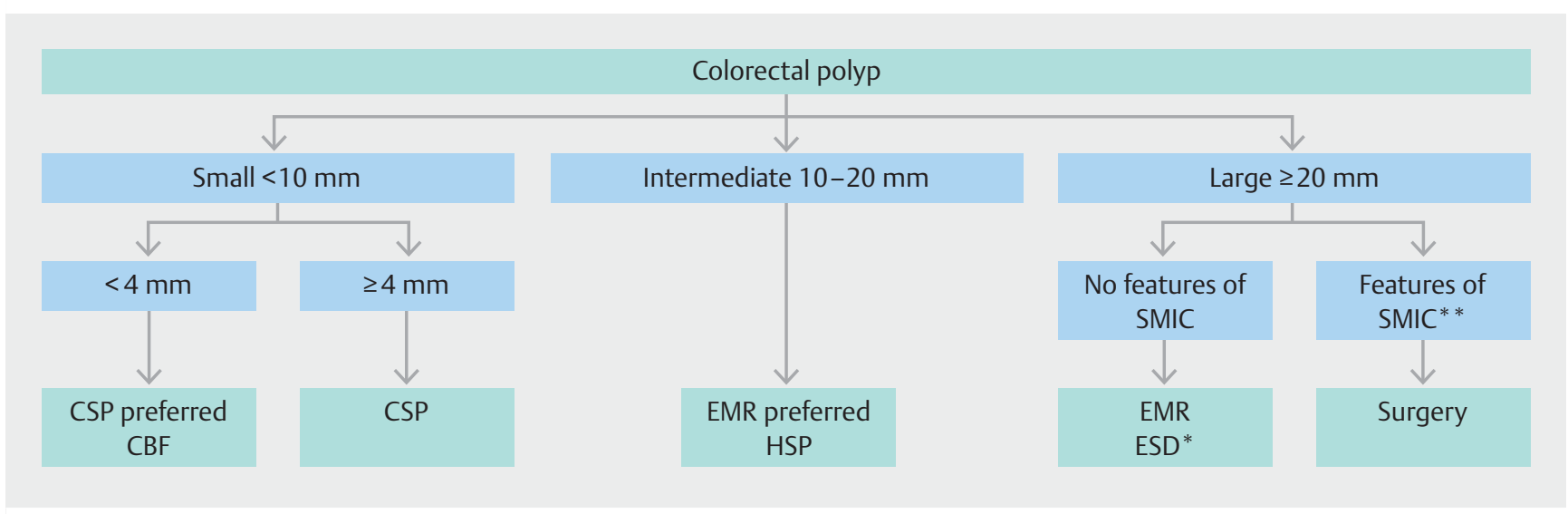

Fig. 1 Overview of recommendations from the guideline. Evidence-based recommendations from the ESGE Colorectal Polypectomy Guideline 2017 [11] represented graphically. This flow diagram was used to assess adherence of participant responses in the study. CSP, cold snare polypectomy; CBF, cold biopsy forceps polypectomy; EMR, endoscopic mucosal resection or hot snare polypectomy with a submucosal lift; HSP, hot snare polypectomy without submucosal lifting; ESD, endoscopic submucosal dissection; SMIC, submucosal invasive cancer. ${ }^{*}$ Consider ESD correct only if rectal and if morphology suggests higher risk for submucosal invasive cancer. ${ }^{* *}$ Outside the rectum or endoscopic imaging evidence of deep SMIC.

incomplete, particularly depending on the operator and the size and type of polyp [4].

The effectiveness of polypectomy is limited by several factors. Training in polypectomy is not standardized nor is it a focus in many countries. Many practitioners work in relatively isolated environments and receive little feedback on their technique or the occurrence of adverse events including PCCRC following their procedures. Importantly, until recently, there was no evidence-based guideline upon which to base decisions about the most effective polypectomy technique to be used in specific situations.

Moreover, recent advances have led to key principles in polypectomy practice. Avoidance of diathermy-related adverse events for resection of small and diminutive $(<10 \mathrm{~mm})$ polyps through the use of cold snare polypectomy (CSP) is well established [5-10]. There is also strong evidence for the superiority of endoscopic resection versus surgery for predicted-benign large colorectal neoplasia [11-14]. There is no published evidence as to whether these messages have reached the wider international community of endoscopists.

The European Society of Gastrointestinal Endoscopy (ESGE) has recently released a thoroughly researched position statement [11] with evidence-based guidelines for the optimal polypectomy technique based on size of polyp. The recommendations are summarized in $\mathbf{F i g . 1}$. The aim of this study was to compare the stated practice of endoscopists in seven countries with this synthesis of the best available contemporary evidence.

\section{Methods}

\section{Definitions}

Throughout this manuscript, "the guideline" refers to the ESGE Colorectal Polypectomy Guideline 2017 [11]. Participant refers to a single endoscopist taking the survey.
Detailed demographic information was collected from participants. In this study, the term "physician" is used to describe a medically trained endoscopist (gastroenterologist). Cold biopsy forceps polypectomy (CBF) refers to the use of a biopsy forceps to remove a polyp in one or more bites. CSP refers to the use of any endoscopic snare to mechanically resect a polyp without the use of diathermy. Hot snare polypectomy (HSP) refers to the use of any endoscopic resection snare to resect a polyp using diathermy without injection of a submucosal lifting solution. HSP with a prior submucosal lift is referred to as endoscopic mucosal resection (EMR). Endoscopic submucosal dissection (ESD) describes the use of an electrosurgical knife to circumferentially incise the mucosa and then dissect the polyp en bloc. Right colon location is defined as proximal to and including the hepatic flexure. Surgical referral describes referral to a surgeon for a traditional surgical resection.

Polyp size categories were $<10 \mathrm{~mm}, 10-19 \mathrm{~mm}$, and $\geq 20 \mathrm{~mm}$. Correct management for each category was assigned according to the technique(s) recommended in the guideline ( $\triangleright$ Fig. 1 ), as a surrogate for the best available contemporary evidence with which colonoscopic practitioners would be expected to be upto-date. Pedunculated polyps were intentionally excluded from the images and the discussion.

\section{Survey design}

Survey questions were based on the standards set forth in the guideline. All authors were required to answer all questions in the first draft of the survey. The final survey reflected refinements based on their responses and suggestions. All authors reviewed and agreed the final version of the survey.

Participating countries were Australia, Belgium, Canada, Israel, New Zealand, UK, and USA. The only differences between survey versions sent to endoscopists in different countries were in the questions regarding demographics. Institutional review board approval for the survey design was obtained from Wes- 
Which technique would you use to resect the displayed lesions in your day-to-day practice?

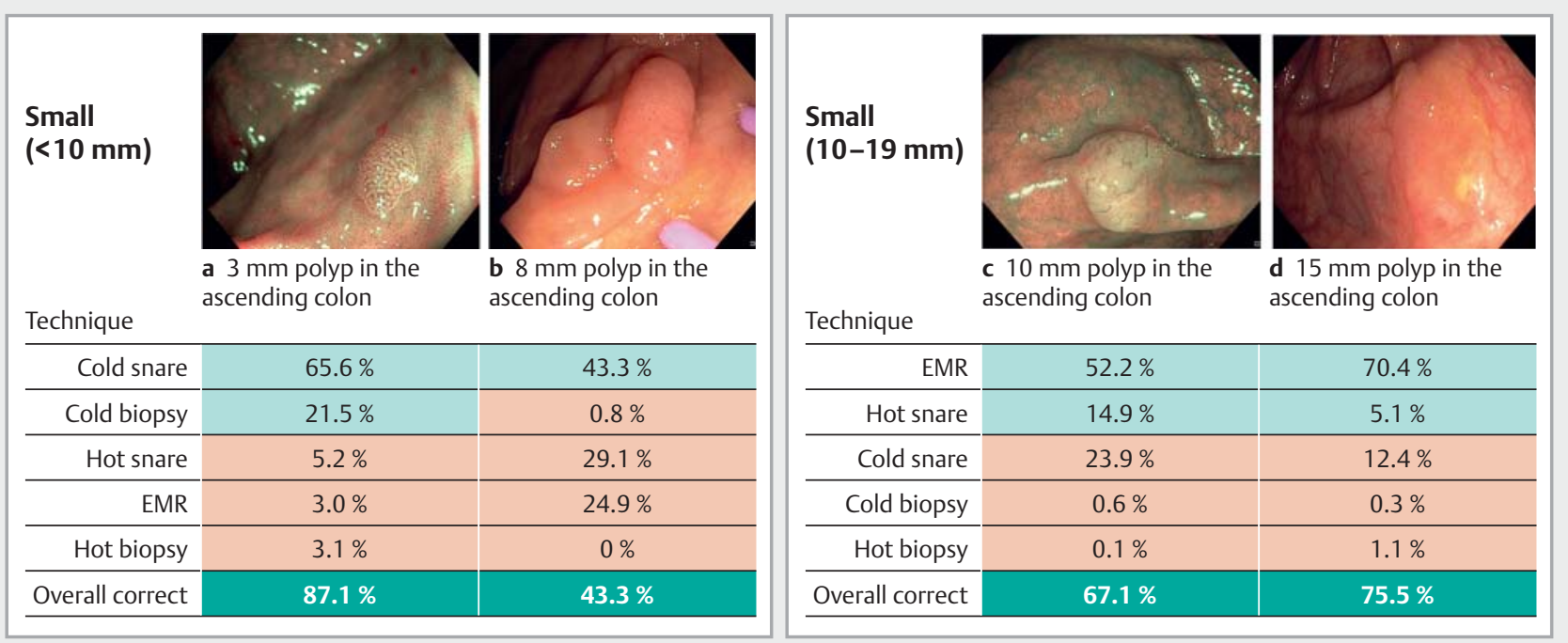

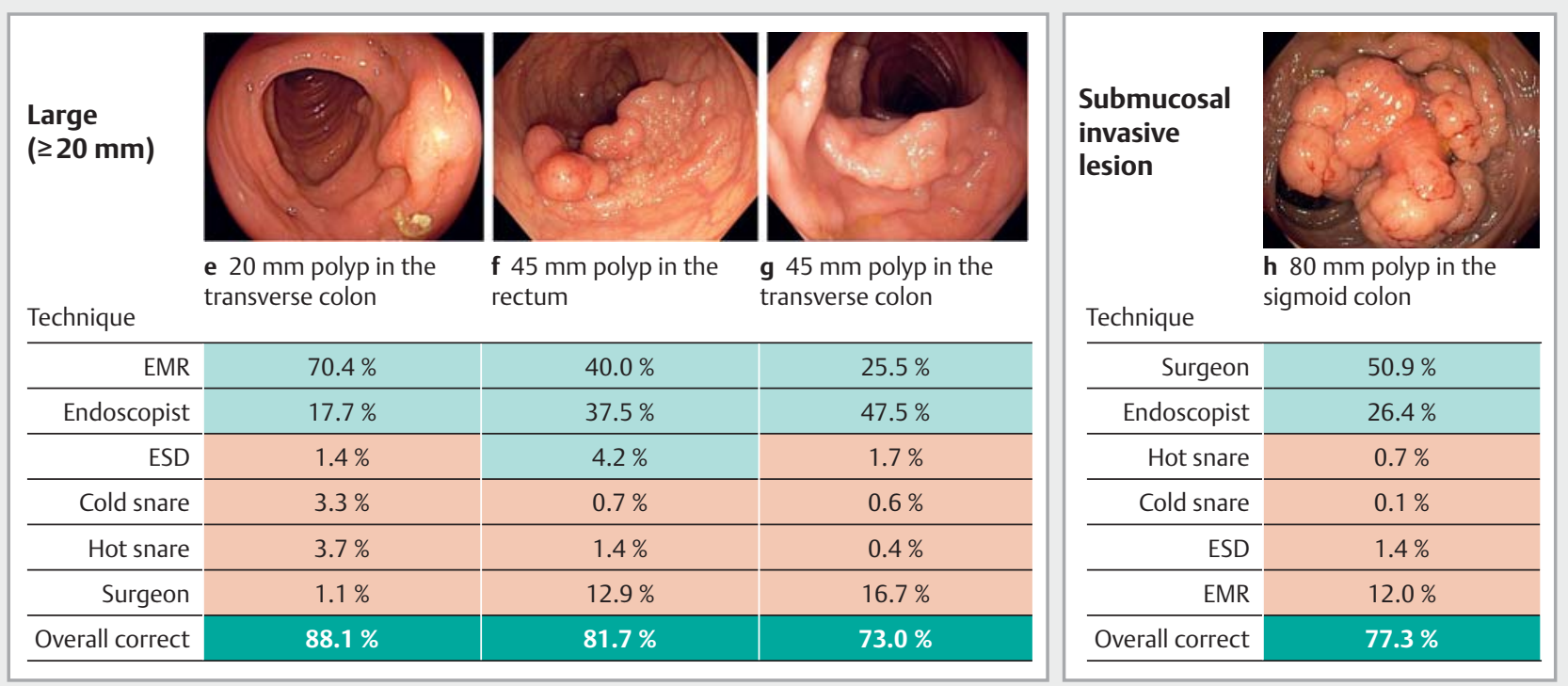

- Fig. 2 Images of polyps presented to study participants stratified by size with resection technique or decision to refer. The text beneath the polyp images represents the exact text presented to the survey participants. Green typeface indicates a correct response when compared with the ESGE Colorectal Polypectomy Guideline. Cold snare, cold snare polypectomy; Cold biopsy, cold biopsy forceps polypectomy; Hot snare, hot snare polypectomy without submucosal lifting; EMR, endoscopic mucosal resection (hot snare polypectomy with prior submucosal lifting); Hot biopsy, hot biopsy forceps polypectomy; Correct, indicates percentage of respondents who chose a correct response as defined by the ESGE Colorectal Polypectomy Guideline. A small minority of respondents chose responses not included on this figure and so percentages do not necessarily add up to $100 \%$.

tern Sydney Local Health District Human Research Ethics Committee and individual countries as required.

The survey contained three sections-participant demographics, images of specific polyps and questions regarding correct polypectomy techniques, and questions regarding the nuances of polypectomy.

The section presenting eight still images of specific polyps ( $\triangleright$ Fig.2) constituted the majority of the survey. Participants were asked to specify the technique they would use in their daily practice to resect the displayed polyp. The images were chosen and agreed by the investigators as typical examples of the polyp size categories presented in the guideline. All techniques were presented as possibilities for every polyp.

\section{Dissemination}

Gastrointestinal endoscopy societies of the countries involved were contacted by the investigators and invited to participate in the survey. Participating societies sent an email to members of their mailing lists. The USA version of the survey was disseminated using a marketing mailing list (Supplementary Table 1). The online survey tool (SurveyMonkey, San Mateo, California, United States) recorded the IP address of each respondent. 
Each participant was asked to enter a random unique identifier at the end of the survey to protect against multiple responses from an individual.

Emails were sent in all countries within July 2017. Two weeks later, a reminder email was sent. After 4 weeks, the survey was closed and the responses analyzed.

\section{Analysis}

The study data were analyzed using IBM SPSS Statistics, Version 23 (IBM Corp, Armonk, New York, United States). Incomplete responses were not analyzed. Categorical variables were correlated using the chi-squared test. Continuous variables were analyzed using either Student $t$ test (two-tailed) or Mann-Whitney $U$ test. If categorized, continuous data were described using the median value. All authors had access to the study data and reviewed the final manuscript.

\section{Results}

In total, 19467 endoscopists in seven countries received the survey; 772 (4.0\%) responded and 707 (91.7\%) completed the survey.

\section{Demographic data (Supplementary Table 2)}

In total, 162/707 respondents identified their location of practice as Australia, 102 Belgium, 60 Canada, 52 Israel, 45 New Zealand, 131 the UK, and 155 the USA. Supplementary Table 2 shows per country responses. In total, 627/707 $(88.7 \%)$ were gastroenterologists, 71 (10.0\%) were surgeons, and 9 (1.3\%) were nurse endoscopists; 63 (8.9\%) were trainees; 312 (44.1\%) identified their practice as academic.

Respondents had performed endoscopy for a median of 18 years (IQR 10-27) and most commonly performed $>20$ colonoscopies per week (25.9\%); 327 (46.3\%) had undertaken a specific endoscopy training attachment of $\geq 6$ months and 243 $(34.4 \%)$ received tertiary referrals for polypectomy.

\section{Polyp analysis and resection \\ ( $>$ Fig. 2, > Table 1, > Fig. 2 and 3)}

All polyps presented in the survey and the responses regarding their management in the daily practice of respondents are displayed in > Fig. 2. Subgroup analyses of these responses by demographic are presented in > Fig. $\mathbf{3}$ (practitioner type), > Table 1 (practitioner type, trainee status, undertaking of a specific endoscopy attachment, referral endoscopist, performing $11+$ or $20+$ colonoscopies per week, academic location of practice, performing 17 + EMRs per year, and 18 + years of total practice), and Supplementary Fig. 1 (country of practice). Correctness of responses was assessed using the flow reported in $>$ Fig. $\mathbf{1}$.

\section{Small $(<10 \mathrm{~mm})$ polyps}

In total, 302 (42.7\%) participants correctly identified management for both small polyps; $152(21.5 \%)$ indicated they would remove a $3 \mathrm{~mm}$ ascending colon polyp ( $>$ Fig. 2a) using CBF and 22 (3.1\%) using hot biopsy forceps (HBF); 206 (29.1\%) indicated they would remove an $8 \mathrm{~mm}$ ascending colon polyp ( $\triangleright$ Fig. 2b) using HSP and 176 (24.9\%) using EMR.
Surgeons were more likely to remove the $3 \mathrm{~mm}$ polyp using HBF $(12.7 \%$ versus $2.1 \%, P<0.001)$ and less likely to use CSP (36.6\% versus $69.1 \%, P<0.001$ ) ( Fig. 3 ). Overall, practitioners performing $>11$ colonoscopies/week $(46.3 \%$ versus $35.9 \%, P=$ 0.008 ) and academic practitioners $(49.0 \%$ versus $37.7 \%, P=$ 0.003 ) were more likely to identify correct management and surgeons less likely than physicians (26.8\% versus $44.2 \%, P=$ 0.005) ( Table 1).

\section{Intermediate (10-19 $\mathrm{mm}$ ) polyps}

In total, 433 (61.2\%) study participants correctly managed both intermediate sized polyps; 169 (23.9\%) indicated they would remove a $10 \mathrm{~mm}$ polyp in the ascending colon ( $>$ Fig. 2c) using CSP and 105 (14.9\%) using HSP; 88 (12.4\%) would have removed a $15 \mathrm{~mm}$ ascending colon polyp ( $\triangleright$ Fig. 2 d) using CSP and 36 (5.1\%) using HSP. Surgeons were more likely to remove the $10 \mathrm{~mm}$ polyp using HSP (29.6\% versus $13.4 \%, P=$ 0.006) ( Fig. 3).

\section{Large ( $\geq 20 \mathrm{~mm}$ ) polyps}

A total of 416 (58.8\%) participants correctly identified management for all large polyps; 26 (3.7\%) would remove a $20 \mathrm{~mm}$ transverse colon polyp ( $\triangleright$ Fig. 2e) using HSP and 10 (1.4\%) using ESD; 125 (17.7\%) would have referred this polyp to another endoscopist for resection and $8(1.1 \%)$ to a surgeon; 283 (40.0\%) would have performed piecemeal EMR on a $45 \mathrm{~mm}$ mid-rectal polyp ( Fig. 2f) while 265 (37.5\%) would have referred it to a tertiary endoscopist; 30 (4.2\%) would have performed ESD themselves while 10 (1.4\%) would have attempted HSP; 91 (12.9\%) would have referred it to a surgeon for resection. A minority of respondents would have elected to remove a $45 \mathrm{~mm}$ transverse colon polyp ( $\mathbf{F i g . 2} \mathbf{g}$ ) using EMR themselves (180, $25.5 \%)$, with the majority 336 (47.5\%) preferring to refer this polyp to a tertiary endoscopist; 118 (16.7\%) would have referred this polyp to a surgeon for resection.

Surgeons were significantly less likely to make correct decisions regarding large polyps (19, $26.8 \%$ versus $277,44.2 \%$, $P<0.001)$. In particular, for the two largest polyps, surgeons were more likely to refer for surgical resection than physicians (33.8\% versus $10.2 \%, P<0.001$ and $22.5 \%$ versus $16.1 \%, P<0.001$, respectively) ( $>$ Fig. 3 ).

\section{Specifics of large ( $\geq 20 \mathrm{~mm}$ ) polyp resection or referral}

Those who indicated they would resect the $45 \mathrm{~mm}$ transverse polyp themselves (28\%) were asked if they would biopsy the polyp before resection ( $15.1 \%$ would) and whether they would remove the polyp in the same session it was detected $(28.1 \%$ would) ( Fig.4). The majority (71.9\%) indicated they would perform the procedure at a later date, $41.2 \%$ due to a perceived need for specific consent for this procedure.

Of those who elected to refer (64\%) the polyp, $47.1 \%$ indicated they would refer to a tertiary endoscopist and $16.7 \%$ to a surgeon. When referring to a surgeon, $88.1 \%$ would have biopsied the polyp and $95.8 \%$ would have marked the position with a carbon particle suspension (tattoo). When referring to a ter- 
- Table 1a Correct decision making regarding colorectal polypectomy stratified by demographic cohort factors compared to the standards in the ESGE polypectomy guideline.

\begin{tabular}{|c|c|c|c|c|c|c|c|c|c|}
\hline \multirow{2}{*}{$\begin{array}{l}\text { Polyp } \\
\text { type } \\
\text { n (\%) } \\
{[95 \% \mathrm{Cl}]}\end{array}$} & \multicolumn{3}{|c|}{ Practitioner type $^{1}$} & \multicolumn{3}{|l|}{ Trainee } & \multicolumn{3}{|c|}{ Specific endoscopy attachment } \\
\hline & Phys & Surg & $P$ value & Cons & Trainee & $P$ value & Yes & No & $P$ value \\
\hline Small & $\begin{array}{l}277(44.2) \\
{[40.3-48.1]}\end{array}$ & $\begin{array}{l}19(26.8) \\
{[17.9-38.1]}\end{array}$ & 0.005 & $\begin{array}{l}278(43.2) \\
{[39.4-47.0]}\end{array}$ & $\begin{array}{l}24(38.1) \\
{[27.1-50.5]}\end{array}$ & 0.437 & $\begin{array}{l}133(40.7) \\
{[35.5-46.1]}\end{array}$ & $\begin{array}{l}169(44.5) \\
{[39.6-49.5]}\end{array}$ & 0.308 \\
\hline $\begin{array}{l}\text { Inter- } \\
\text { mediate }\end{array}$ & $\begin{array}{l}386(61.6) \\
{[57.7-65.3]}\end{array}$ & $\begin{array}{l}45(63.4) \\
{[51.8-73.6]}\end{array}$ & 0.765 & $\begin{array}{l}398(61.8) \\
{[58.0-65.5]}\end{array}$ & $\begin{array}{l}35(55.6) \\
{[43.3-67.2]}\end{array}$ & 0.331 & $\begin{array}{l}213(65.1) \\
{[59.8-70.1]}\end{array}$ & $\begin{array}{l}220(57.9) \\
{[52.9-62.8]}\end{array}$ & 0.049 \\
\hline Large & $\begin{array}{l}391(62.4) \\
{[58.5-66.1]}\end{array}$ & $\begin{array}{l}21(29.6) \\
{[20.2-41.0]}\end{array}$ & $<0.001$ & $\begin{array}{l}378(58.7) \\
{[54.9-62.4]}\end{array}$ & $\begin{array}{l}38(60.3) \\
{[48.0-71.5]}\end{array}$ & 0.803 & $\begin{array}{l}175(53.5) \\
{[48.1-58.9]}\end{array}$ & $\begin{array}{l}241(63.4) \\
{[58.5-68.1]}\end{array}$ & 0.008 \\
\hline $\begin{array}{l}\text { Predicted } \\
\text { SMIC }\end{array}$ & $\begin{array}{l}484(77.2) \\
{[73.8-80.3]}\end{array}$ & $\begin{array}{l}55(77.5) \\
{[66.5-85.6]}\end{array}$ & 0.959 & $\begin{array}{l}490(76.1) \\
{[72.7-79.2]}\end{array}$ & $\begin{array}{l}57(90.5) \\
{[80.7-95.6]}\end{array}$ & 0.009 & $\begin{array}{l}240(73.4) \\
{[68.4-77.9]}\end{array}$ & $\begin{array}{l}307(80.8) \\
{[76.5-84.4]}\end{array}$ & 0.019 \\
\hline $\begin{array}{l}\text { Total per } \\
\text { subgroup }\end{array}$ & 627 & 71 & & 644 & 63 & & 327 & 380 & \\
\hline \multicolumn{10}{|c|}{$\begin{array}{l}\text { Polyp size criteria (small, intermediate, large) are defined in the } \\
\text { evidence of submucosal invasive cancer (SMIC). Phys, physician; } \\
\text { practitioner. Specific endoscopy attachment, undertaken a speci } \\
95 \% \mathrm{Cl}, 95 \% \text { confidence interval of the proportion above. } \\
P \text { values in bold typeface indicate significance at the } 0.05 \text { level. } \\
{ }^{1} \text { Denominator } 698 \text { after removing nurse endoscopists }(n=9) \text {. }\end{array}$} \\
\hline
\end{tabular}

- Table 1b Correct decision making regarding colorectal polypectomy stratified by demographic cohort factors compared to the standards in the ESGE polypectomy guideline.

\begin{tabular}{|c|c|c|c|c|c|c|c|c|c|}
\hline \multirow{2}{*}{$\begin{array}{l}\text { Polyp } \\
\text { type } \\
\text { n (\%) } \\
{[95 \% \mathrm{Cl}]}\end{array}$} & \multicolumn{3}{|l|}{ Referral } & \multicolumn{3}{|l|}{$11+$ colons } & \multicolumn{3}{|l|}{$20+$ colons } \\
\hline & Yes & No & $P$ value & Yes & No & $P$ value & Yes & No & $P$ value \\
\hline Small & $\begin{array}{l}92(37.9) \\
{[32.0-44.1]}\end{array}$ & $\begin{array}{l}210(45.3) \\
{[40.8-49.8]}\end{array}$ & 0.059 & $\begin{array}{l}214(46.3) \\
{[41.8-50.9]}\end{array}$ & $\begin{array}{l}88(35.9) \\
{[30.2-42.1]}\end{array}$ & 0.008 & $\begin{array}{l}87(47.5) \\
{[40.4-54.8]}\end{array}$ & $\begin{array}{l}215(41.0) \\
{[36.9-45.3]}\end{array}$ & 0.125 \\
\hline $\begin{array}{l}\text { Inter- } \\
\text { mediate }\end{array}$ & $\begin{array}{l}164(67.5) \\
{[63.4-73.1]}\end{array}$ & $\begin{array}{l}269(58.0) \\
{[53.4-62.4]}\end{array}$ & 0.014 & $\begin{array}{l}292(63.2) \\
{[58.7-67.5]}\end{array}$ & $\begin{array}{l}141(57.6) \\
{[51.3-63.6]}\end{array}$ & 0.142 & $\begin{array}{l}105(57.4) \\
{[50.1-64.3]}\end{array}$ & $\begin{array}{l}328(62.6) \\
{[58.4-66.6]}\end{array}$ & 0.212 \\
\hline Large & $\begin{array}{l}146(60.1) \\
{[53.8-66.0]}\end{array}$ & $\begin{array}{l}270(58.2) \\
{[53.7-62.6]}\end{array}$ & 0.627 & $\begin{array}{l}266(57.6) \\
{[53.0-62.0]}\end{array}$ & $\begin{array}{l}150(61.2) \\
{[55.0-67.1]}\end{array}$ & 0.348 & $\begin{array}{l}103(56.3) \\
{[49.0-63.3]}\end{array}$ & $\begin{array}{l}313(59.7) \\
{[55.5-63.8]}\end{array}$ & 0.414 \\
\hline $\begin{array}{l}\text { Predicted } \\
\text { SMIC }\end{array}$ & $\begin{array}{l}132(54.3) \\
{[48.0-60.5]}\end{array}$ & $\begin{array}{l}415(89.4) \\
{[86.3-92.0]}\end{array}$ & $<0.001$ & $\begin{array}{l}357(77.3) \\
{[73.2-80.9]}\end{array}$ & $\begin{array}{l}190(77.6) \\
{[71.9-82.3]}\end{array}$ & 0.933 & $\begin{array}{l}132(72.1) \\
{[65.2-78.1]}\end{array}$ & $\begin{array}{l}415(79.2) \\
{[75.5-82.5]}\end{array}$ & 0.049 \\
\hline $\begin{array}{l}\text { Total per } \\
\text { subgroup }\end{array}$ & 243 & 464 & & 462 & 245 & & 183 & 524 & \\
\hline \multicolumn{10}{|c|}{$\begin{array}{l}\text { Polyp size criteria (small, intermediate, large) are defined in the Methods section and in } \mathbf{F i g . 1} \text {. Predicted SMIC refers to the } 80 \mathrm{~mm} \text { sigmoid polyp with endoscopic } \\
\text { evidence of submucosal invasive cancer (SMIC). Referral, practitioner reports receiving referrals for colonoscopic polypectomy; } 11+\text { colons, practitioner reports per- } \\
\text { forming } 11 \text { or more colonoscopies per week; } 20+\text { colons, practitioner reports performing } 20 \text { or more colonoscopies per week; } 95 \% \mathrm{Cl}, 95 \% \text { confidence interval of the } \\
\text { proportion above. } \\
P \text { values in bold typeface indicate significance at the } 0.05 \text { level. }\end{array}$} \\
\hline
\end{tabular}

tiary endoscopist, $35.4 \%$ would have biopsied the polyp and $59.2 \%$ marked the position with tattoo.

In total, $8 \%$ of respondents suggested other management strategies, mainly calling for multidisciplinary discussion before a decision or biopsy before a decision on final management.

\section{Polyp with endoscopic evidence of submucosal invasive cancer (SMIC)}

In total, 360 (50.9\%) participants correctly identified that the $80 \mathrm{~mm}$ polyp in the sigmoid colon contained an endoscopically demarcated area consistent with SMIC and suggested surgical referral ( $>$ Fig. 2 h); 187 (26.4\%) suggested referral to a tertiary 
- Table 1c Correct decision making regarding colorectal polypectomy stratified by demographic cohort factors compared to the standards in the ESGE polypectomy guideline.

\begin{tabular}{|c|c|c|c|c|c|c|c|c|c|c|}
\hline \multirow{2}{*}{$\begin{array}{l}\text { Polyp } \\
\text { type } \\
\text { n (\%) } \\
{[95 \% \mathrm{Cl}]}\end{array}$} & \multicolumn{3}{|l|}{ Academic } & \multicolumn{3}{|l|}{17 + EMRs } & \multicolumn{3}{|c|}{$18+$ years' practice } & \multirow[t]{2}{*}{ Overall } \\
\hline & Yes & No & $P$ value & Yes & No & $P$ value & Yes & No & $P$ value & \\
\hline Small & $\begin{array}{l}153(49.0) \\
{[43.5-54.6]}\end{array}$ & $\begin{array}{l}149(37.7) \\
{[33.1-42.6]}\end{array}$ & 0.003 & $\begin{array}{l}80(31.5) \\
{[26.1-37.5]}\end{array}$ & $\begin{array}{l}222(49.0) \\
{[44.4-53.6]}\end{array}$ & $<0.001$ & $\begin{array}{l}140(39.7) \\
{[34.7-44.9]}\end{array}$ & $\begin{array}{l}162(45.8) \\
{[40.6-51.0]}\end{array}$ & 0.101 & $\begin{array}{l}302 \\
(42.7)\end{array}$ \\
\hline $\begin{array}{l}\text { Inter- } \\
\text { mediate }\end{array}$ & $\begin{array}{l}185(59.3) \\
{[53.8-64.6]}\end{array}$ & $\begin{array}{l}248(62.8) \\
{[57.9-67.4]}\end{array}$ & 0.344 & $\begin{array}{l}189(74.4) \\
{[68.7-79.4]}\end{array}$ & $\begin{array}{l}244(53.9) \\
{[49.3-58.4]}\end{array}$ & $<0.001$ & $\begin{array}{l}220(62.3) \\
{[57.2-67.2]}\end{array}$ & $\begin{array}{l}213(60.2) \\
{[55.0-65.1]}\end{array}$ & 0.557 & $\begin{array}{l}433 \\
(61.2)\end{array}$ \\
\hline Large & $\begin{array}{l}198(63.5) \\
{[58.0-68.6]}\end{array}$ & $\begin{array}{l}218(55.2) \\
{[50.3-60.0]}\end{array}$ & 0.026 & $\begin{array}{l}145(57.1) \\
{[50.9-63.0]}\end{array}$ & $\begin{array}{l}271(59.8) \\
{[55.2-64.2]}\end{array}$ & 0.478 & $\begin{array}{l}198(56.1) \\
{[50.9-61.2]}\end{array}$ & $\begin{array}{l}218(61.6) \\
{[56.4-66.5]}\end{array}$ & 0.138 & $\begin{array}{l}416 \\
(58.8)\end{array}$ \\
\hline $\begin{array}{l}\text { Predicted } \\
\text { SMIC }\end{array}$ & $\begin{array}{l}229(73.4) \\
{[68.2-78.0]}\end{array}$ & $\begin{array}{l}229(80.5) \\
{[53.1-62.7]}\end{array}$ & 0.025 & $\begin{array}{l}168(66.1) \\
{[60.1-71.7]}\end{array}$ & $\begin{array}{l}379(83.7) \\
{[80.0-86.8]}\end{array}$ & $<0.001$ & $\begin{array}{l}262(74.2) \\
{[69.4-78.5]}\end{array}$ & $\begin{array}{l}285(80.5) \\
{[76.1-84.3]}\end{array}$ & 0.046 & $\begin{array}{l}547 \\
(77.4)\end{array}$ \\
\hline $\begin{array}{l}\text { Total per } \\
\text { subgroup }\end{array}$ & 312 & 395 & & 254 & 453 & & 353 & 354 & & 707 \\
\hline \multicolumn{11}{|c|}{$\begin{array}{l}\text { Polyp size criteria (small, intermediate, large) are defined in the Methods section and in } \$ \text { Fig. } 1 \text {. Predicted SMIC refers to the } 80 \mathrm{~mm} \text { sigmoid polyp with endoscopic } \\
\text { evidence of submucosal invasive cancer (SMIC). Academic, practitioner reports at least part of their practice in an academic institution; } 17+\text { EMRs, practitioner re- } \\
\text { ports performing } 17 \text { or more endoscopic mucosal resection procedures for polyps } \geq 20 \mathrm{~mm} \text { per year; } 18+\text { years' practice, practitioner reports } 18 \text { or more years of } \\
\text { continuous practice as a consultant or independent practitioner; } 95 \% \mathrm{Cl}, 95 \% \text { confidence interval of the proportion above. } \\
P \text { values in bold typeface indicate significance at the } 0.05 \text { level. }\end{array}$} \\
\hline
\end{tabular}

endoscopist; 95 (13.4\%) would attempt to remove the polyp themselves, $12.0 \%$ using EMR and $1.4 \%$ using ESD.

Surgeons were more likely to directly refer this polyp to surgery than physicians (69.0\% versus $48.8 \%, P<0.001)$ ( $>$ Fig. 3 ). Academic practice $(P=0.025)$, more than 20 colonoscopies performed per week $(P=0.049)$, more than 17 EMRs per year $(P<$ $0.001)$, and 18 +years' total independent practice $(P=0.046)$ identified practitioners significantly less likely to identify correct management of this polyp ( $\triangleright$ Table 1 ).

\section{Specific polypectomy techniques}

In total, 508/675 (75.3\%) respondents routinely use carbon dioxide insufflation during colonoscopy and polypectomy ( $\triangleright$ Table 2); 423/694 (61.0\%) use a thin wire snare (diameter $<0.4 \mathrm{~mm})$ for CSP.

In total, 516/692 (74.6\%) routinely take measures to prevent bleeding from the stalks of pedunculated polyps with stalk diameter $>10 \mathrm{~mm}$ (most often clip placement over the polyp stalk, 216/516 [41.9\%]).

The most common snare diameter reported for EMR was $15 \mathrm{~mm}$ in the right colon [237/645, 36.7\%] and $20 \mathrm{~mm}$ in the left colon [223/644, 34.5\%]. The most common injection solution was saline $(352 / 660,53.3 \%)$. Adrenaline/epinephrine was added to the injectate by $407 / 681$ (59.8\%). A chromic dye was added to the injectate by $501 / 686(73.0 \%)$, and most commonly this was Methylene Blue (295, 43.0\%).

In total, $77 / 674(11.4 \%)$ of respondents reported performing ESD in the rectum and $44 / 673(6.2 \%)$ in the rest of the coIon.

\section{Variation in polyp analysis and resection techniques between countries}

Australian endoscopists were most likely to identify the correct management of small polyps (77.8\%) and Belgians were the least likely $(16.7 \%, P<0.001)$ (Supplementary Fig. 1). For intermediate polyps, Australian endoscopists identified correct management least often (35.8\%) versus Canadians who had the highest rates $(76.7 \%, P<0.001)$. Large polyp management was most often correctly identified by Australian endoscopists (74.7\%) and least often by those from the United States (34.2\%, $P<0.001)$. Belgian endoscopists most often correctly suggested management of the polyp with SMIC (84.3\%).

\section{Discussion}

Colorectal cancer may be prevented by high-quality colonoscopy and complete polypectomy. It is increasingly recognized that the safety and completeness of polypectomy depend upon the technique used. We analyzed the responses of 707 endoscopists in seven countries to a survey designed to assess their practice against a contemporary synthesis of the available evidence in colorectal polypectomy [11]. The results demonstrate areas for focused interventions to improve polypectomy practice and therefore patient outcomes.

The 2017 ESGE Colorectal Polypectomy Guideline offers an excellent synthesis of the contemporary evidence for technique choice in polypectomy, stratified by polyp size and is freely available from the organization's website. The standards set forth in the guideline had been clear from important publications in peer-reviewed journals on the subject $[12,13]$ and the accumulating publications on the safety and efficacy of CSP 
Which technique would you use to resect the displayed lesions in your day-to-day practice?

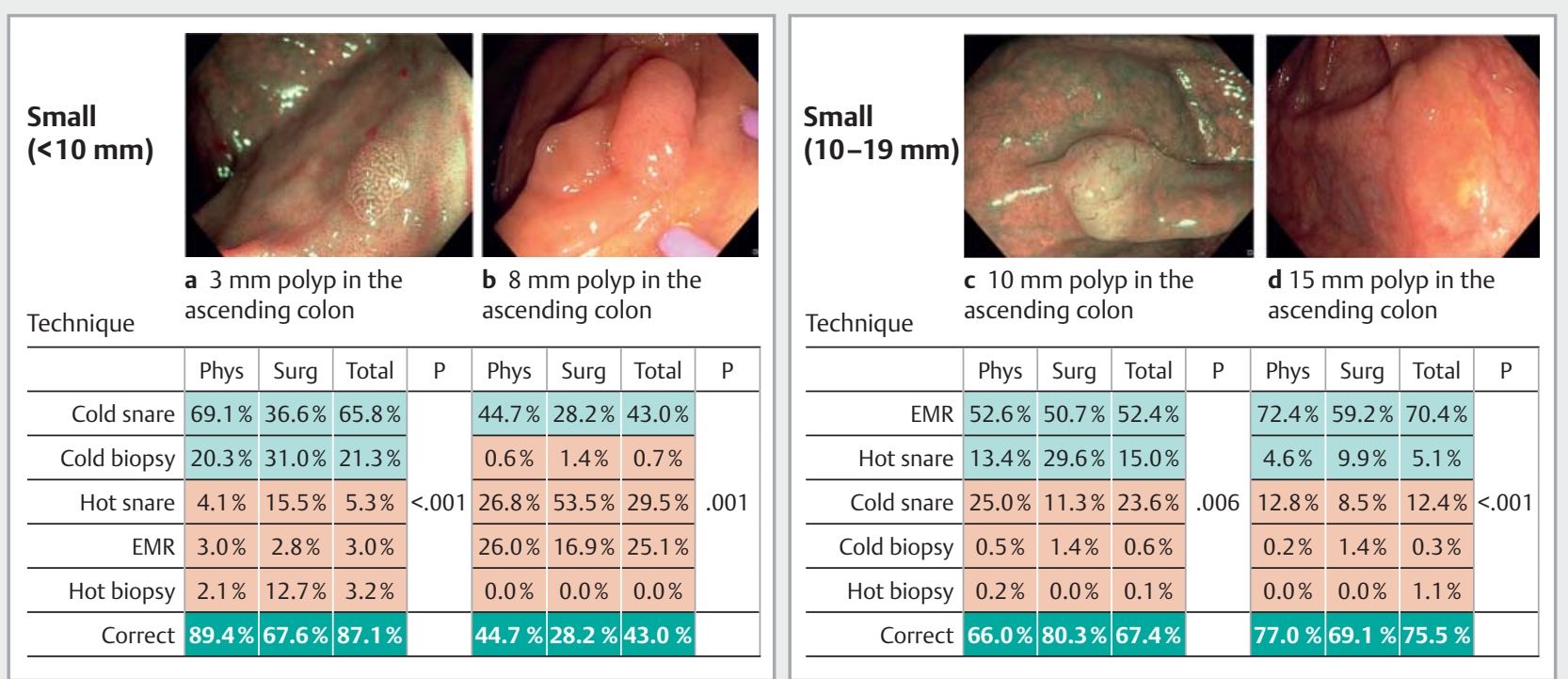

\begin{tabular}{|c|c|c|c|c|c|c|c|c|c|c|c|c|}
\hline \multicolumn{13}{|l|}{$\begin{array}{l}\text { Large } \\
\text { ( } \geq 20 \mathrm{~mm})\end{array}$} \\
\hline \multirow[t]{2}{*}{ Technique } & \multicolumn{4}{|c|}{$\begin{array}{l}\text { e } 20 \mathrm{~mm} \text { polyp in the } \\
\text { transverse colon }\end{array}$} & \multicolumn{4}{|c|}{$\begin{array}{l}\text { f } 45 \mathrm{~mm} \text { polyp in the } \\
\text { rectum }\end{array}$} & \multicolumn{4}{|c|}{$\begin{array}{l}\text { g } 45 \text { mm polyp in the } \\
\text { transverse colon }\end{array}$} \\
\hline & Phys & Surg & Total & $P$ & Phys & Surg & Total & $P$ & Phys & Surg & Total & $P$ \\
\hline EMR & $71.9 \%$ & $63.4 \%$ & $71.1 \%$ & \multirow{6}{*}{.002} & $40.0 \%$ & $42.3 \%$ & $40.3 \%$ & \multirow{6}{*}{$<.001$} & $25.5 \%$ & $28.2 \%$ & $25.8 \%$ & \multirow{6}{*}{$<.001$} \\
\hline Endoscopist & $17.7 \%$ & $12.7 \%$ & $17.2 \%$ & & $40.4 \%$ & $11.3 \%$ & $37.4 \%$ & & $49.8 \%$ & $19.7 \%$ & $46.7 \%$ & \\
\hline ESD & $1.6 \%$ & $0.0 \%$ & $1.4 \%$ & & $4.6 \%$ & $1.4 \%$ & $4.3 \%$ & & $1.8 \%$ & $1.4 \%$ & $1.7 \%$ & \\
\hline Cold snare & $3.0 \%$ & $4.2 \%$ & $3.2 \%$ & & $0.6 \%$ & $1.4 \%$ & $0.7 \%$ & & $0.6 \%$ & $0.0 \%$ & $0.6 \%$ & \\
\hline Hot snare & $2.9 \%$ & $11.3 \%$ & $3.7 \%$ & & $1.3 \%$ & $2.8 \%$ & $1.4 \%$ & & $0.5 \%$ & $0.0 \%$ & $0.4 \%$ & \\
\hline Surgeon & $1.1 \%$ & $1.4 \%$ & $1.1 \%$ & & $10.2 \%$ & $33.8 \%$ & $12.6 \%$ & & $16.1 \%$ & $22.5 \%$ & $16.8 \%$ & \\
\hline Correct & $89.6 \%$ & $76.1 \%$ & $88.3 \%$ & & $85.4 \%$ & $55.0 \%$ & $82.0 \%$ & & $75.3 \%$ & $47.9 \%$ & $72.5 \%$ & \\
\hline
\end{tabular}

\begin{tabular}{|c|c|c|c|c|}
\hline \multirow{3}{*}{$\begin{array}{l}\text { Submucosa } \\
\text { invasive } \\
\text { lesion }\end{array}$} & \multirow{2}{*}{\multicolumn{4}{|c|}{$\begin{array}{l}\text { h } 80 \mathrm{~mm} \text { polyp in the } \\
\text { sigmoid colon }\end{array}$}} \\
\hline & & & & \\
\hline & Phys & Surg & Total & $P$ \\
\hline Surgeon & $48.8 \%$ & $69.0 \%$ & $50.9 \%$ & \multirow{5}{*}{$<.001$} \\
\hline Endoscopist & $28.4 \%$ & $8.5 \%$ & $26.4 \%$ & \\
\hline Hot snare & $0.3 \%$ & $4.2 \%$ & $0.7 \%$ & \\
\hline Cold snare & $0.2 \%$ & $0.0 \%$ & $0.1 \%$ & \\
\hline ESD & $1.6 \%$ & $0.0 \%$ & $1.4 \%$ & \\
\hline EMR & $12.6 \%$ & $8.5 \%$ & $12.2 \%$ & \\
\hline Correct & $77.2 \%$ & $77.5 \%$ & $77.3 \%$ & \\
\hline
\end{tabular}

Fig. 3 Images of polyps presented to study participants stratified by size with resection technique or decision to refer further stratified by type of practitioner. The text beneath the polyp image represents the exact text presented to the survey participants. Green typeface indicates a correct response when compared with the ESGE Colorectal Polypectomy Guideline. Phys, physician; Surg, surgeon; Cold snare, cold snare polypectomy; Cold biopsy, cold biopsy forceps polypectomy; Hot snare, hot snare polypectomy without submucosal lifting; EMR,-endoscopic mucosal resection (hot snare polypectomy with prior submucosal lifting); Hot biopsy, hot biopsy forceps polypectomy; Correct, indicates percentage of respondents who chose a correct response as defined by the ESGE Colorectal Polypectomy Guideline. Nurse endoscopists are excluded from this figure, total $n=698$. A small minority of respondents chose responses not included on this figure and so percentages do not necessarily add up to $100 \%$.

$[14,15]$, the risks of HBF $[16,17]$, and the efficacy and superior safety profile of endoscopic resection versus surgery [18-21] over the prior decade. It is incumbent upon all medical practitioners to remain up-to-date with the evidence in their field of practice. Therefore, we used the guideline as a benchmark against which to assess the polypectomy practice of individual endoscopists against the best contemporary evidence at the time of the survey.
The lowest rates of adherence to the guideline were regarding resection of the smallest polyps $(<10 \mathrm{~mm})$. CSP is the preferred technique here (CBF considered to be a second-line option for polyps $\geq 3 \mathrm{~mm}$ where CSP is "technically difficult"). Recent data reinforce the safety [7], and efficacy of CSP in achieving en bloc resection and adenoma clearance in addition to its comparative efficacy versus HSP $[5,6]$. The small polyps pres- 


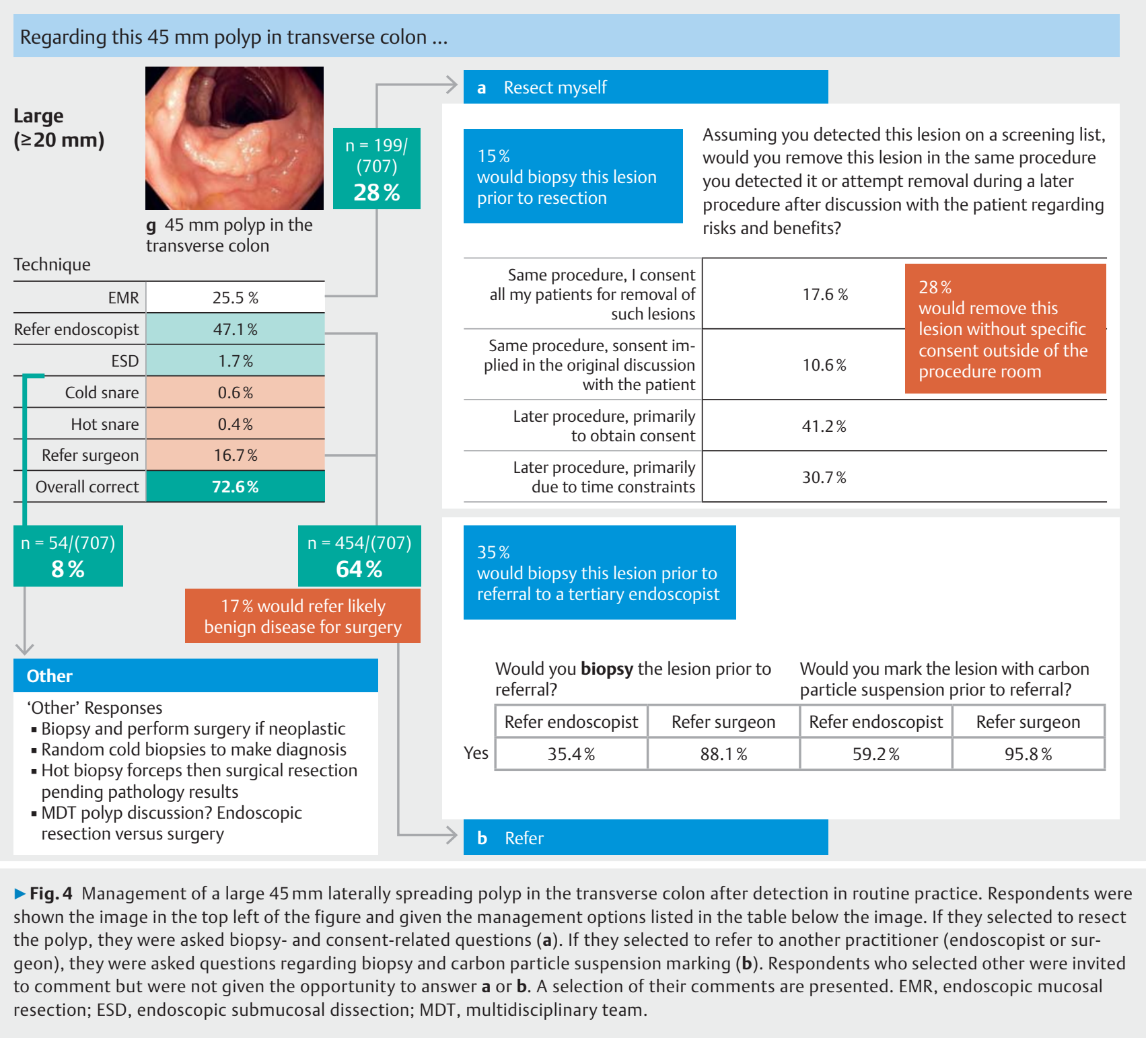

ented were located in the right colon where the risk profile of diathermy is highest.

While encouraging numbers of respondents indicated they would perform CSP or CBF for the $3 \mathrm{~mm}$ ascending colon polyp, for an $8 \mathrm{~mm}$ polyp in the same location, $>50 \%$ of respondents indicated they would perform EMR or, of greater concern, HSP (without a submucosal lift) in their daily practice. This suggests unnecessary exposure of patients to the small yet definite risks of diathermy, namely delayed bleeding [22] and post-polypectomy syndrome [15]. A particular focus for the promotion of CSP should be non-academic practitioners performing smaller numbers of colonoscopies since these groups demonstrated lower adherence in this category.

A small number of respondents stated that they would perform $\mathrm{HBF}$ to resect the $3 \mathrm{~mm}$ ascending colon polyp. Animal [16] and clinical [17] studies suggest HBF should be avoided due to the possibility of full thickness colonic injury and poor rates of complete resection. Surgeons were significantly more likely to suggest HBF as a response. The message that HBF should be avoided must be further promoted in this context.

Higher rates of adherence to the guideline were recorded regarding intermediate $(10-19 \mathrm{~mm})$ polyps. HSP (without submucosal injection) or EMR are recommended here but deep thermal injury is a potential risk with HSP and submucosal injection is strongly recommended. Respondents expressed a preference for EMR over HSP in the majority of cases regarding both polyps. Only $15 \%$ indicated they would remove the $10 \mathrm{~mm}$ polyp and $5 \%$ the $15 \mathrm{~mm}$ right colon polyp with HSP; those responding in this way were more commonly surgeons. Therefore, although the guideline suggests HSP is acceptable, it is clearly not the practice of the majority of study respondents or that of the authors, particularly in the right colon.

Correct management of all large polyps was identified by $60 \%$ of respondents overall. Polyps $\geq 20 \mathrm{~mm}$ in size (>90\%) can 
- Table 2 Specific polypectomy techniques identified by respondents. Number of respondents to each question identified separately since not all participants answered all questions, and unlike responses to the questions regarding specific polyps, this did not disqualify their data from analysis.

\section{Respondents}

\section{Cold snare polypectomy}

What type of snare do you use for cold snare polypectomy?
- Thin wire snare (snare wire diameter $<0.4 \mathrm{~mm}$ )
$423(61.0 \%)$
- Thick wire snare (snare wire diameter $\geq 0.4 \mathrm{~mm}$ )
$106(15.3 \%)$
- Don't know $165(23.8 \%)$
- Total
694

\section{Pedunculated polypectomy}

Do you take routine measures to prevent bleeding from pedunculated polyps with stalk diameter greater than $10 \mathrm{~mm}$ ?

\begin{tabular}{|l|c|}
\hline - Yes & $516(74.6 \%)$ \\
\hline - No & $176(25.4 \%)$ \\
\hline - Total & 692 \\
\hline General polypectomy & \\
\hline $\begin{array}{l}\text { Do you routinely use carbon dioxide insufflation during colonoscopy } \\
\text { and polypectomy? }\end{array}$ & $508(75.3 \%)$ \\
\hline - Yes & $166(24.6 \%)$ \\
\hline - No & $1(0.1 \%)$ \\
\hline - Don't know & 675 \\
\hline - Total
\end{tabular}

Do you routinely (or frequently) use dye spraying (chromo-endoscopy) to evaluate colon polyps?

\begin{tabular}{|l|l|}
\hline . Yes & $82(12.2 \%)$ \\
\hline " No & $592(87.8 \%)$ \\
\hline . Total & 674 \\
\hline
\end{tabular}

Do you routinely (or frequently) use optical or digital image enhancement (NBI, FICE, etc.) to evaluate colon polyps?

\begin{tabular}{|l|c|}
\hline - Yes & $497(73.7 \%)$ \\
\hline - No & $177(26.3 \%)$ \\
\hline " Other (please specify) & $0(0.0 \%)$ \\
\hline " Total & 674 \\
\hline
\end{tabular}

Do you perform endoscopic submucosal dissection (ESD) in the rectum?

\begin{tabular}{|l|l|}
\hline - Yes & $77(11.4 \%)$ \\
\hline - No & $597(88.6 \%)$ \\
\hline - Total & 674 \\
\hline \multicolumn{2}{|l|}{ Do you perform ESD in the remainder of the colon? } \\
\hline - Yes & $44(6.2 \%)$ \\
\hline - No & $629(89.0 \%)$ \\
\hline - Total & $673(100.0 \%)$ \\
\hline
\end{tabular}

- Table 2 (Continuation)

\section{Respondents}

\section{Submucosal lift polypectomy-(endoscopic mucosal resection-} EMR)

What size snare do you most commonly use for a standard submucosal lift polypectomy (EMR) in the right colon? (proximal and including the hepatic flexure)

\begin{tabular}{|l|c|}
\hline . $10 \mathrm{~mm}$ & $110(17.1 \%)$ \\
\hline - $15 \mathrm{~mm}$ & $237(36.7 \%)$ \\
\hline - $20 \mathrm{~mm}$ & $172(26.7 \%)$ \\
\hline - Other snare size & $51(7.9 \%)$ \\
\hline - Don't know & $75(11.6 \%)$ \\
\hline
\end{tabular}

What size snare do you most commonly use for a standard submucosal lift polypectomy (EMR) in the left colon? (distal to the hepatic flexure)

\begin{tabular}{|l|c|}
\hline - $10 \mathrm{~mm}$ & $79(12.2 \%)$ \\
\hline - $15 \mathrm{~mm}$ & $218(33.7 \%)$ \\
\hline - $20 \mathrm{~mm}$ & $223(34.5 \%)$ \\
\hline - Other snare size & $52(8.0 \%)$ \\
\hline - Don't know & $74(11.5 \%)$ \\
\hline - Total & 646 \\
\hline
\end{tabular}

If you perform submucosal injection before snare resection or EMR, what do you use as the injection solution?

\begin{tabular}{|l|c|}
\hline - Saline & $352(53.3 \%)$ \\
\hline - Succinylated gelatin (e. g. Gelofusine) & $4(0.6 \%)$ \\
\hline - Starch (e. g. Voluven) & $235(36.1 \%)$ \\
\hline - Hyaluronic acid & $54(8.2 \%)$ \\
\hline - Other & $12(1.8 \%)$ \\
\hline - Total & 660 \\
\hline
\end{tabular}

Do you routinely add adrenaline/epinephrine to your injection solution for submucosal lift polypectomy (EMR)

\begin{tabular}{|l|l|}
\hline - Yes & $274(40.2 \%)$ \\
\hline - No & $407(59.8 \%)$ \\
\hline - Total & 681 \\
\hline
\end{tabular}

Do you routinely add a chromic dye to your injection solution for submucosal lift polypectomy (EMR)?

- Yes, Indigo Carmine $193(28.1 \%)$

- Yes, Methylene Blue $295(43.0 \%)$

- No $185(27.0 \%)$

- Other dye $13(1.9 \%)$

- Total 686 
be safely and effectively resected in a single session using EMR $[20,23]$ without resorting to surgery with its higher risk of morbidity and mortality $[18,24]$. Therefore patients have much to gain from correct responses in this category.

The majority of respondents suggested endoscopic management for a $20 \mathrm{~mm}$ polyp in the transverse colon and felt comfortable undertaking this themselves. Conversely, only $40 \%$ suggested they would attempt a $45 \mathrm{~mm}$ rectal polyp themselves and $26 \%$ a $45 \mathrm{~mm}$ transverse colon polyp. Given the cohort bias, this suggests the majority of endoscopists prefer to refer large laterally spreading polyps to a tertiary endoscopist. Of significant concern, $13 \%$ suggested they would refer the rectal polyp for surgery and $17 \%$ the transverse colon polyp. This is supported by recent US data indicating the rate of surgery for non-malignant colorectal polyps is high (9.4/100000 adults) and has increased over the past 14 years [25]. Surgeons and non-academic endoscopists were more likely to refer benign disease for surgery. This finding suggests that the establishment of review pathways for endoscopic images of large colorectal polyps by expert endoscopists before surgical referral is necessary.

Almost all respondents indicated they would biopsy and mark a polyp being referred for surgery with tattoo. The authors agree with this practice. If referring to a tertiary endoscopist, only $1 / 3$ would biopsy the polyp (even with "hindsight") and 2/3 would mark the polyp with tattoo. Anecdotal evidence indicates that both practices are associated with fibrosis at endoscopic resection so the authors take a common-sense approach of marking subtle polyps at least $2 \mathrm{~cm}$ distally and biopsying only superficially and if there is concern for SMIC.

A third of respondents indicated they would remove the $45 \mathrm{~mm}$ transverse polyp (if detected on a screening list) at the session it was detected without specific consent. Presuming the patient is sedated, the authors would recommend specific consent be obtained before endoscopic resection of such a polyp. Reasons include the higher rates of delayed bleeding, hospital admission, adenoma recurrence and the need for further surgery than polypectomy of smaller polyps. Patients should also be informed of the available alternative management options including observation, alternative endoscopic techniques, or surgery.

One in four respondents did not recognize that an $80 \mathrm{~mm}$ sigmoid polyp contained overt evidence of SMIC and suggested endoscopic resection was appropriate. Interestingly, those with a longer practice duration and academic practice were less likely to answer correctly. Consideration should be given to the development of training schemes incorporating endoscopic imaging for practicing endoscopists to avoid unnecessary repeat procedures for patients (either after tertiary endoscopist referral of an endoscopically unresectable polyp, or due to a failed endoscopic resection attempt of the same).

The technical polypectomy data from the survey provide interesting insights into real-world polypectomy practice when compared to the best available evidence. In particular, $11 \%$ of respondents reported performing ESD in the rectum and $6 \%$ in the remainder of the colon. This demonstrates the expertise bias within the survey cohort but taking this into consideration, also demonstrates that ESD is not performed by the vast majority of endoscopists in the countries surveyed.

This study has some limitations. The response rate to the study was low. In addition, the use of a marketing mailing list for dissemination of the survey in the USA garnered a particularly low response rate and may have biased the results. Before use of a marketing list, we approached the largest endoscopy organization in that country, but it declined to participate.

Studies with similar methodology had response rates of 13$45 \%$ [26-30,31], but significantly lower response pools (maximum 5030 versus 19467 in this study) and therefore significantly fewer respondents [excepting the US only study [29]]. Such a large study on polypectomy with > 700 complete responses and contributions from seven Western countries has not previously been described. Due to the low response rate, there is a significant risk of non-response bias. To mitigate this as far as possible, multiple, focused questions to address potentially confounding demographics were included in the survey. The responses to these suggested the respondents are a self-selected group with extensive experience and with an interest in endoscopy. The results should be interpreted in this context. Indeed, while this cannot be proven, the practice of non-respondents could reasonably be expected to be less adherent than that of respondents.

Still single images were used for the questions regarding polyp management. While not a substitute for in vivo polyp assessment, similar judgments must often be made from previously acquired images (often single and of low quality) provided for referral purposes. All authors confirmed the polyp images as representative before circulation of the survey. The power of individual, anonymous reporting of images to judge current practice should not be underestimated. Rigid classifications were used to judge adherence of participant responses to guidelines. We acknowledge that individual cases must be judged using clinical acumen, and guidelines are not a substitute for this.

The number of surgeons and trainees in this study was small compared to the overall cohort. Despite this, statistical significance was demonstrated, however, we accept the possibility of bias within the small group of individuals recruited.

\section{Conclusions}

Responses of over 700 colonoscopists in seven countries suggest that CSP is underutilized for diminutive polypectomy despite its favorable safety and similar efficacy profile compared to alternative techniques requiring diathermy. Benign colorectal neoplasia is routinely referred for surgery. Overt SMIC is underappreciated using endoscopic imaging amongst a self-selected group of interested endoscopic practitioners. Addressing these issues via focused interventions by international endoscopy societies may reduce burdens of diathermy-related adverse events, surgery, and unnecessary colonoscopic procedures on patients, in addition to potentially reducing rates of PCCRC. 


\section{Competing interests}

The authors declare that they have no conflict of interest.

\section{References}

[1] Winawer S], Zauber AG, Ho MN. The National Polyp Study Workgroup. et al. Prevention of colorectal cancer by colonoscopic polypectomy. NEJM 1993; 329: 1977-1981

[2] Zauber AG, Winawer S], O'Brien M] et al. Colonoscopic polypectomy and long-term prevention of colorectal-cancer deaths. NEJM 2012; 366: 687-696

[3] Corley DA, Jensen CD, Marks AR et al. Adenoma detection rate and risk of colorectal cancer and death. NEJM 2014; 370: 1298-1306

[4] Pohl H, Srivastava A, Bensen SP et al. Incomplete polyp resection during colonoscopy - Results of the complete adenoma resection (CARE) study. Gastroenterology 2013; 144: 74-80.e1

[5] Suzuki S, Gotoda T, Kusano C et al. Width and depth of resection for small colorectal polyps: hot versus cold snare polypectomy. Gastrointest Endosc 2018; 87: 1095-1103

[6] Shinozaki S, Kobayashi Y, Hayashi Y et al. Efficacy and safety of cold versus hot snare polypectomy for resecting small colorectal polyps: Systematic review and meta-analysis. Dig Endosc 2018; 30: 592-599

[7] Papastergiou V, Paraskeva KD, Fragaki M et al. Cold versus hot endoscopic mucosal resection for nonpedunculated colorectal polyps sized 6-10 mm: a randomized trial. Endoscopy 2018; 50: 403-411

[8] Jung YS, Park CH, Nam E et al. Comparative efficacy of cold polypectomy techniques for diminutive colorectal polyps: a systematic review and network meta-analysis. Surg Endosc 2018; 32: 1149-1159

[9] Maruoka D, Arai M, Akizue $\mathrm{N}$ et al. Residual adenoma after cold snare polypectomy for small colorectal adenomas: a prospective clinical study. Endoscopy 2018; 50: 693-700

[10] Dwyer JP, Tan JYC, Urquhart P et al. A prospective comparison of cold snare polypectomy using traditional or dedicated cold snares for the resection of small sessile colorectal polyps. Endosc Int Open 2017; 5: E1062-1068

[11] Ferlitsch M, Moss A, Hassan C et al. Colorectal polypectomy and endoscopic mucosal resection (EMR): European Society of Gastrointestinal Endoscopy (ESGE) Clinical Guideline. Endoscopy 2017; 49: 270-297

[12] Burgess NG, Bahin FF, Bourke MJ. Colonic polypectomy (with videos). Gastrointest Endosc 2015; 81: 813-835

[13] Hewett DG. Colonoscopic polypectomy. Current techniques and controversies. Gastroenterol Clin North Am 2013; 42: 443-458

[14] Lee CK, Shim J-J, Jang JY. Cold snare polypectomy vs. Cold forceps polypectomy using double-biopsy technique for removal of diminutive colorectal polyps: a prospective randomized study. Am J Gastroenterol 2013; 108: 1593-1600

[15] Ichise $Y$, Horiuchi A, Nakayama $Y$ et al. Prospective randomized comparison of cold snare polypectomy and conventional polypectomy for small colorectal polyps. Digestion 2011; 84: 78-81
[16] Metz AJ, Moss A, McLeod D et al. A blinded comparison of the safety and efficacy of hot biopsy forceps electrocauterization and conventional snare polypectomy for diminutive colonic polypectomy in a porcine model. Gastrointest Endosc 2013; 77: 484-490

[17] Komeda Y, Kashida H, Sakurai T et al. Removal of diminutive colorectal polyps: A prospective randomized clinical trial between cold snare polypectomy and hot forceps biopsy. World J Gastroenterol 2017; 23: 328-335

[18] Ahlenstiel G, Hourigan LF, Brown G et al. Actual endoscopic versus predicted surgical mortality for treatment of advanced mucosal neoplasia of the colon. Gastrointest Endosc 2014; 80: 668-676

[19] Jayanna M, Burgess NG, Singh R et al. Cost analysis of endoscopic mucosal resection vs surgery for large laterally spreading colorectal lesions. Clin Gastroenterol Hepatol 2016; 14: 271-272

[20] Moss A, Bourke M], Williams S] et al. Endoscopic mucosal resection outcomes and prediction of submucosal cancer from advanced colonic mucosal neoplasia. Gastroenterology 2011; 140: 1909-1918

[21] Moss A, Williams S], Hourigan LF et al. Long-term adenoma recurrence following wide-field endoscopic mucosal resection (WF-EMR) for advanced colonic mucosal neoplasia is infrequent: results and risk factors in 1000 cases from the Australian Colonic EMR (ACE) study. Gut 2015; 64: 57-65

[22] Horiuchi A, Nakayama Y, Kajiyama M et al. Removal of small colorectal polyps in anticoagulated patients: A prospective randomized comparison of cold snare and conventional polypectomy. Gastrointest Endosc 2014; 79: 417-423

[23] Hassan C, Repici A, Sharma P et al. Efficacy and safety of endoscopic resection of large colorectal polyps: a systematic review and meta-analysis. Gut 2016; 65: 806-820

[24] Keswani RN, Law R, Ciolino JD et al. Adverse events after surgery for nonmalignant colon polyps are common and associated with increased length of stay and costs. Gastrointest Endosc 2016; 84: 296303.e1

[25] Peery AF, Cools KS, Strassle PD et al. Increasing rates of surgery for patients with nonmalignant colorectal polyps in the United States. Gastroenterology 2018; 154: 1352-1353

[26] Barret M, Boustiere C, Canard J-M et al. Factors associated with adenoma detection rate and diagnosis of polyps and colorectal cancer during colonoscopy in France: Results of a prospective, nationwide survey. PLoS One 2013; 8: e68947

[27] Geraghty J, O’Toole P, Anderson J et al. National survey to determine current practices, training and attitudes towards advanced polypectomy in the UK. Frontline Gastroenterol 2015; 6: 85-93

[28] Chandran S, Parker F, Vaughan R et al. The current practice standard for colonoscopy in Australia. Gastrointest Endosc 2014; 79: 473-479

[29] Whitson M], Bodian CA, Aisenberg J et al. Is production pressure jeopardizing the quality of colonoscopy? A survey of U.S. endoscopists' practices and perceptions Gastrointest Endosc 2012; 75: 641-648

[30] Pedersen IB, Løberg M, Hoff G et al. Polypectomy techniques among gastroenterologists in Norway - a nationwide survey. Endosc Int Open 2018; 06: E812-E820

[31] Carter D, Beer-Gabel M, Zbar A et al. A survey of colonoscopic polypectomy practice amongst Israeli gastroenterologists. Ann Gastroenterol 2013; 26: 135-140 